\title{
Studi Awal Pembuatan Serbuk Tembaga Berstruktur Amorf
}

\author{
Yunita Sari \\ Universitas Negeri Jakarta, Fakultas Teknik, Program Studi Pendidikan \\ Teknik Mesin \\ Jalan Rawamangun Muka, Pulogadung, Jakarta Timur \\ E-mail: yunitasari@unj.ac.id
}

\begin{abstract}
Abstrak
Serbuk logam umumnya diproduksi dengan proses atomisasi (sentrifugal, gas, atau air), elektrolisis, atau kimia. Logam umumnya memiliki struktur kristal (crystalline), agar dapat diperoleh serbuk logam berstruktur nonkristal atau amorf (amorphous) maka proses yang dipilih adalah reaksi kimia. Untuk memperoleh serbuk tembaga berstruktur amorf maka dilakukan reaksi antara larutan tembaga (II) sulfat (atau $\mathrm{CuSO}_{4}$ ) dengan logam seng (atau $\mathrm{Zn}$ ) pada temperatur dan kecepatan agitasi yang relatif tinggi. Sedangkan untuk meningkatkan kemurnian logam tembaga (atau $\mathrm{Cu}$ ) yang dihasilkan digunakan gas inert selama berlangsungnya reaksi kimia tersebut. Karakterisasi terhadap serbuk logam yang dihasilkan dilakukan dengan analisis menggunakan sinar x. Aplikasi logam amorf antara lain adalah sebagai material soft-magnetic dan aplikasi yang membutuhkan material amorf yang ketangguhannya lebih tinggi dibandingkan material amorf yang lain seperti keramik. Ini merupakan penelitian awal pembuatan serbuk tembaga berstruktur amorf, sebab untuk bisa memperoleh logam yang nonkristal (metallic glass/glassy metal) adalah hal yang sulit, bahkan untuk memperoleh serbuk logam yang kemurniannya cukup tinggi pun dengan proses ini bukanlah hal yang mudah.
\end{abstract}

Kata kunci: Amorf, Logam, Tembaga, Serbuk

\section{Pendahuluan}

Latar belakang penelitian, umumnya serbuk logam ditemui berstruktur kristal (crystalline), artinya atom-atomnya menempati posisi sesuai dengan suatu pola tiga dimensi tertentu yang teratur dan berulang. Sedangkan untuk aplikasi tertentu diperlukan serbuk logam berstruktur nonkristal atau amorf (amorphous).

Perumusan masalah, apakah serbuk logam berstruktur amorf bisa diperoleh dengan mereduksi suatu larutan senyawa pada temperatur dan kecepatan agitasi yang tinggi.

Tujuan penelitian, membuat serbuk $\mathrm{Cu}$ (Copper) berstruktur amorf dengan mereaksikan larutan $\mathrm{CuSO}_{4}$ (Cupric Sulfate) dan $\mathrm{Zn}$ (Zinc) dengan kecepatan agitasi dan temperatur reaksi yang relatif tinggi.

Ruang Lingkup penelitian, sumber logam tembaga adalah tembaga (II) sulfat pentahidrat atau $\mathrm{CuSO}_{4} .5 \mathrm{H}_{2} \mathrm{O}$. Sedangkan sebagai reduktornya adalah logam seng. Reaksi kimia dilakukan dalam labu kimia berleher tiga menggunakan alat Magnetic
Stirrer sehingga reaksi tersebut dapar berlangsung pada kecepatan agitasi 1450 rpm dan temperatur $70^{\circ}$ C. Selama berlangsungnya reaksi dialirkan gas nitrogen sebagai gas inert. Untuk mengetahui komposisi kimia serbuk yang dihasilkan, maka dilakukan analisis dengan menggunakan XRF ( $X$-Ray Fluorescent) dan XRD ( $X$-Ray Diffractometry), dan juga dilakukan pengamatan morfologi permukaan dengan bantuan SEM (Scanning Electron Microscope).

Hipotesis, Reaksi antara larutan tembaga (II) sulfat dengan logam seng akan menghasilkan endapan logam tembaga sebab berdasarkan deret logam menurut Volta dan Nerst: logam seng akan "mendesak" logam tembaga, atau dengan kata lain ion $\mathrm{Zn}$ akan menggantikan ion $\mathrm{Cu}$ dalam bersenyawa dengan ion $\mathrm{SO}_{4}$. Serbuk tembaga yang dihasilkan diharapkan berstruktur amorf akibat temperatur reaksi dan kecepatan agitasi yang cukup tinggi. 
2. Diagram Alir Penelitian

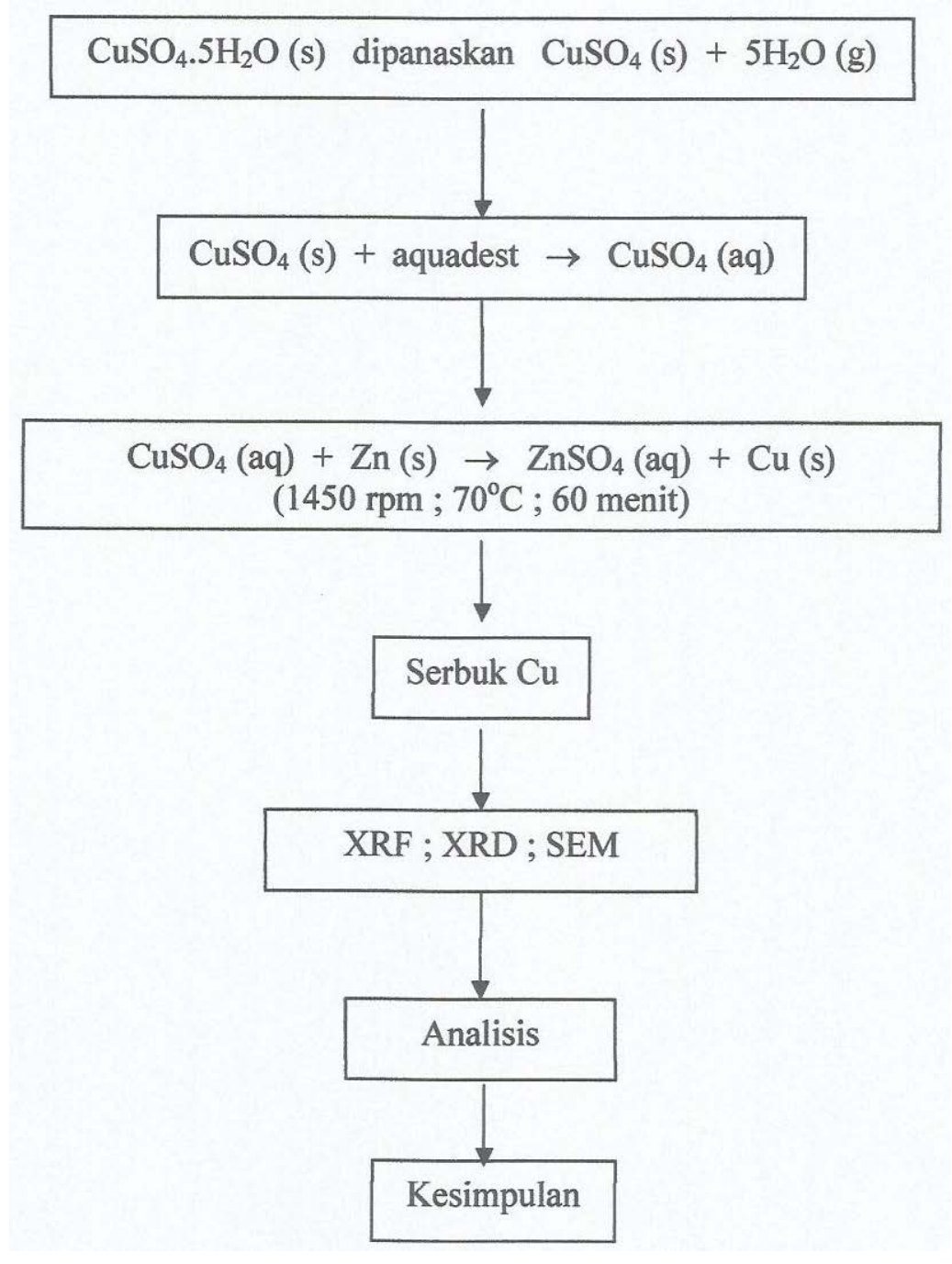

\section{Hasil dan Pembahasan}

Hasil analisis XRF pada Gambar 1 menunjukkan bahwa serbuk terdiri dari 85,23\% $\mathrm{Cu} ; 14,70 \% \mathrm{Zn} ; 0,07 \% \mathrm{Fe}$ (persentase berat). Hasil analisis XRD pada Gambar 2 menunjukkan bahwa serbuk adalah material berstruktur kristalin sebab puncak-puncak pola difraksinya tajam (tidak melebar) dan komposisi kimia serbuk adalah terdiri dari $\mathrm{Cu}$ (data ICDD: $2 \theta=50,7^{\circ}$ ) dan $\mathrm{Cu}_{2} \mathrm{O}$ (data ICDD: $2 \theta=42,7^{\circ}$ ). 


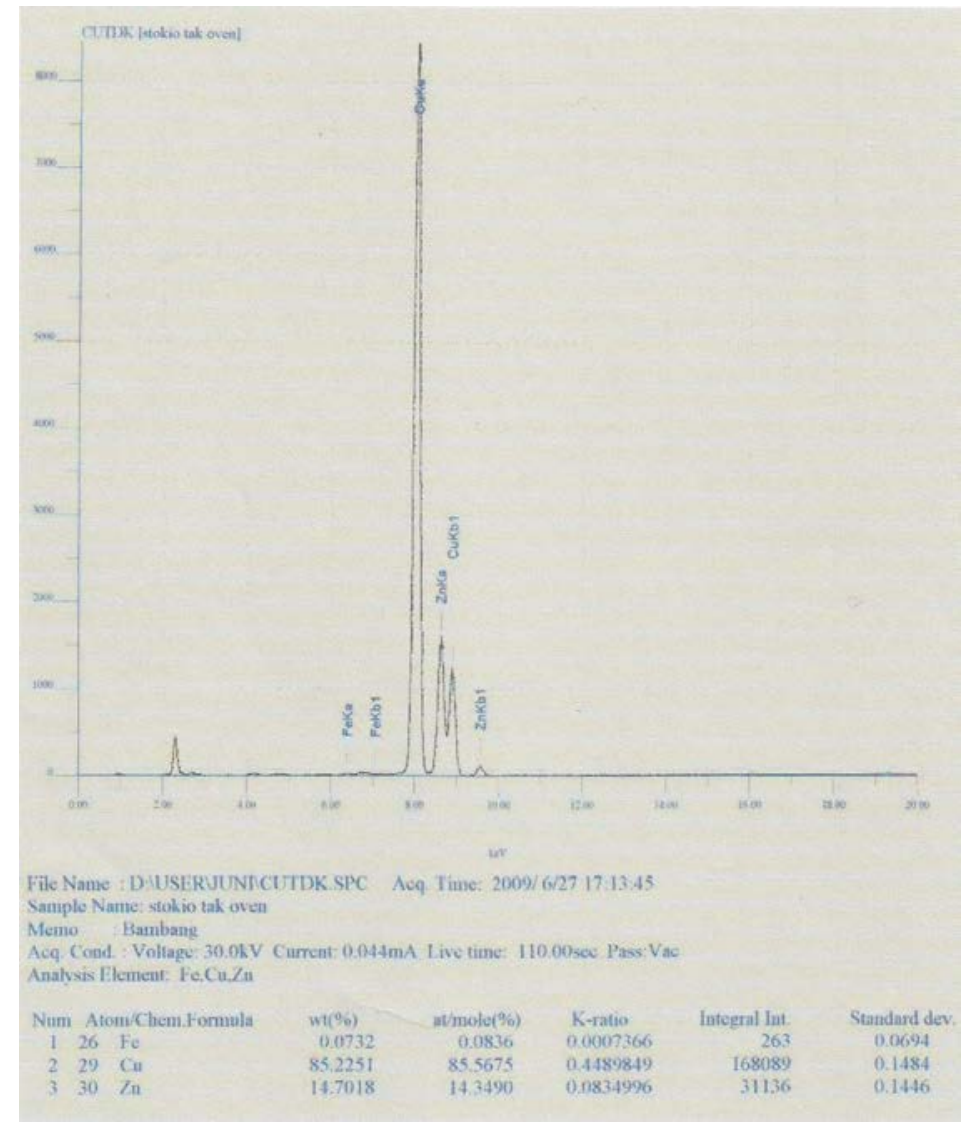

Gambar 1. Hasil XRF

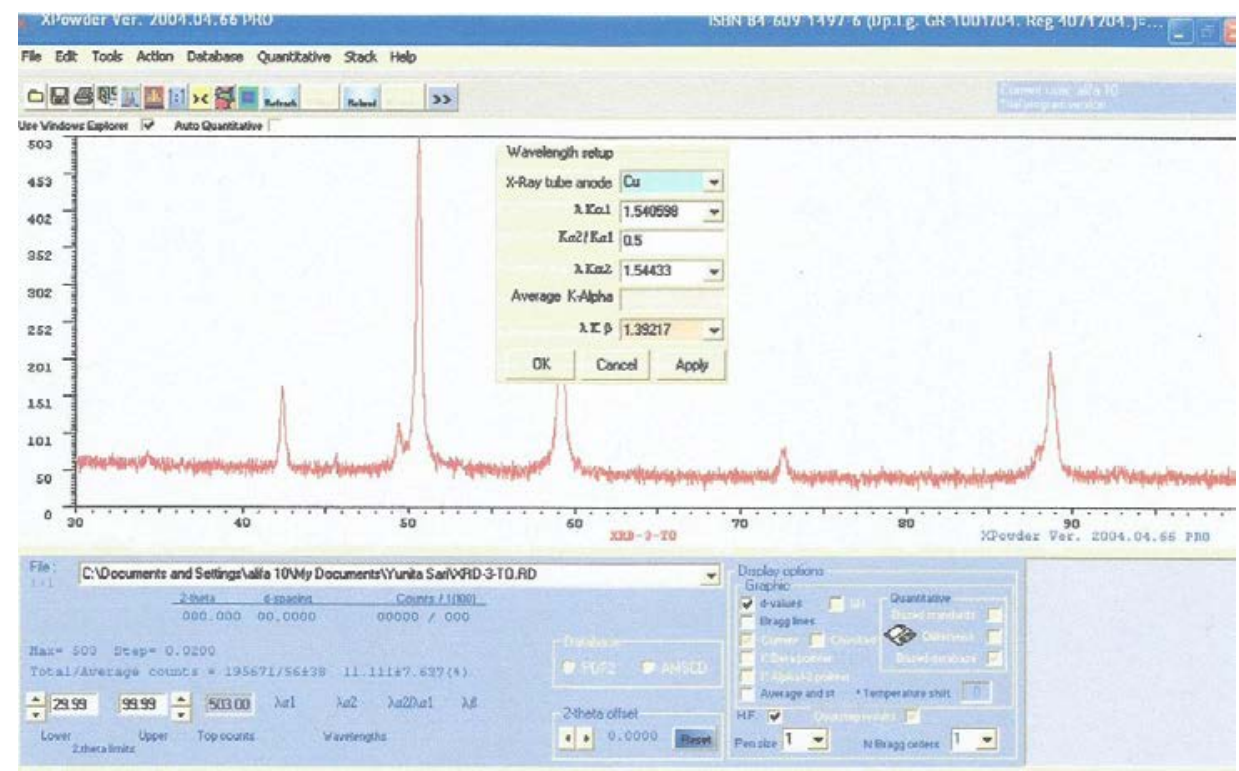

Gambar 2. Hasil XRD 


\section{Kesimpulan}

Reaksi antara larutan $\mathrm{CuSO}_{4}$ dengan $\mathrm{Zn}$ menghasilkan endapan $\mathrm{Cu}$. Sangat sulit memperoleh $\mathrm{Cu}$ murni dengan proses reaksi kimia tersebut sebab sangat sulit untuk melindungi terhadap kontak dengan lingkungan. Serbuk logam tembaga yang diperoleh berstruktur Kristal, diduga temperatur dan kecepatan agitasi kurang cukup tinggi untuk mencegah terjadinya rekristalisasi.

\section{Daftar Pustaka}

[1] Suryanarayana \& Grant Norton; X-Ray Diffraction (A Practical Approach); 1998; Plenum Press, New York.

[2] Serope Kalpakjian \& Steven Schmid; Manufacturing Processes for Engineering Materials, Fourth Edition; Pearson Education, Inc., USA.

[3] Pat L. Mangonon; The Principles of Materials Selection for Engineering Design; 1999; Prentice, Inc.; New Jersey, USA.

[4] Sidney H. Avner; Introduction to Physical Metallurgy, Second Edition; 1988; Fong \& Sons Printers Pte. Ltd., Singapore.

[5] Prof. Sukardjo; Kimia Organik; 1990; Rineka Cipta, Jakarta.

[6] William F. Smith; Principles of Materials Science and Engineering, Third Edition; 1996; McGraw-Hill, Inc., USA.

[7] Robert Reed-Hill \& Reza Abbaschian; Physical Metallurgy Principles, Third Edition; 1994; PWS Publishing Company, Boston.

[8] James A. Jacobs \& Thomas F. Kilduff, Engineering Materials Technology, Prentice-Hall, Inc., New Jersey.

[9] Wang Guang; Study of Mechanical Properties of Amorphous Copper with Molecular Dynamics Simulation; IOP Electronic Journals, Chinese Physics B, 256-263; 2008.
[10] Nicholas De Cristofaro; Amorphous Metals in Electric-Power Distribution Applications; Materials Research Society (MRS) Bulletin, Volume 23, Number 5 (1998), P.50-56.

[11] J. C. Anderson; Materials Science, Fourth Edition; Chapman \& Hall; London; 1990.

[12] P. J. Goodhew \& F. J. Humphreys; Electron Microscopy and Analysis, Second Edition; 1988; Taylor \& Francis Inc., London.

[13] W. Bolton; Engineering Materials Technology, Second Edition; 1993; Newnes, Oxford.

[14] Zbigniew D. Jastrzebski; The Nature and Properties of Engineering Materials, Third Edition; 1987; John Wiley \& Sons, Singapore.

[15] William D. Callister; Materials Science and Engineering (An Introduction), Fourth Edition; 1997; John Wiley \& Sons, Inc.

[16] Albert G. Guy \& John J. Hren; Elements of Physical Metallurgy, Third Edition; 1974; Addison-Wesley Publishing Company, Inc.

[17] Lawrence H. Van Vlack; Materials Science for Engineers; Addition-Wesley Publishing Company; Massachusetts; 1973.

[18] ASM Handbook, Vol. 2; Properties and Selection: Nonferrous Alloys and Special Purpose Materials; ASM International; USA; 1995.

[19] American Society for Metals; Metals Handbook, Desk Edition; Metals Park; Ohio; 1995.

[20] ASM Handbook Vol. 10; Materials Characterization; ASM International; USA; 1992. 